\title{
A Study on Kinetic Mechanisms of Diesel Fuel Surrogate n-dodecane for the Simulation of Combustion Recession
}

\author{
X.H. Fang, R. Ismail and M. H. Davy \\ Department of Engineering Science, University of Oxford, UK
}

Copyright (c) 2018 SAE International

\begin{abstract}
Combustion recession, an end of injection (EOI) diesel spray phenomenon, has been found to be a robust correlation parameter for UHC in diesel LTC strategies. Previous studies have shown that the likelihood of capturing combustion recession in numerical simulations is highly dependent on the details of the low-temperature chemistry reaction mechanisms employed. This study aims to further the understanding of the effects of different chemical mechanisms in the prediction of a reactive diesel spray and its EOI process: combustion recession. Studies were performed under the Engine Combustion Network's (ECN) "Spray A" conditions using the Reynolds-Averaged Navier-Stokes simulation (RANS) and the Flamelet Generated Manifold (FGM) combustion model with four different chemical mechanisms for n-dodecane that are commonly used in the engine simulation communities including recently developed reduced chemistry mechanisms. The flamelet database for each of the chemical mechanism is generated using two methods: 0D homogeneous reactor (HR) ignition flamelets and 1D igniting counterflow diffusion (ICDF) flamelets. The effect of different tabulation approaches is investigated first following by the discussion of the impact of chemical mechanisms on the prediction of combustion recession. Further discussions include an evaluation of the performance of chemical mechanisms in predicting the most relevant reacting spray characteristics compared to the ECN experimental database: ignition delay time (IDT), flame lift-off length (LOL) and flame reactive region. Results show that the choice of both tabulation method and chemical mechanism play a significant role in initial flame stabilization and end of injection (EOI) transient processes. In general, both tabulation techniques were able to qualitatively capture the flame characteristics before EOI, however ICDF tabulation is better suited for the FGM approach in order to capture combustion recession. Furthermore, the chemical mechanisms studied indicate that mechanisms with stronger low temperature chemistry predictions are more likely to promote combustion recession under an FGM framework.
\end{abstract}

\section{Introduction}

Diesel engines are established as one of the most important hydrocarbon fuelled powertrain technologies for ground transportation [21]. However, to meet future requirements of increased efficiency and reduced emissions, various modifications to the basic diesel cycle, such as the use of homogeneous charge compression ignition (HCCI) [13], exhaust gas recirculation (EGR) [25], or some other form of low temperature combustion (LTC) strategy [17], are likely required. LTC, in general, has shown great promise in mitigating emissions of nitrogen oxides $\left(\mathrm{NO}_{x}\right)$ and particulate matter (PM) [30]. While different LTC operating strategies and injection processes greatly influence the final emissions outcomes, end of injection (EOI) processes, in particular, have been found to play a critical role with respect to hydrocarbon emissions. One of the great challenges typically associated with LTC is an overly fuel-lean mixture in the near-nozzle region of the spray, which suppresses second-stage ignition and results in an increase of unburned hydrocarbons (UHC). Recent studies indicate that combustion recession, an end of injection diesel spray phenomenon, is a robust correlation parameter for UHC in diesel LTC [18].

Combustion recession is a physical process which happens immediately after the EOI whereby a lifted flame retracts back towards the nozzle tip, consuming UHC in the near nozzle region. Experimental studies indicate that combustion recession can be influenced by ambient thermodynamic conditions and injector parameters, as well as the details of the EOI transient event itself [29] [5] [19]. Although many experiments have been conducted to qualitatively visualize combustion recession, there are limited combustion simulation studies regarding this phenomenon owing to its transient and unsteady behavior. A comparative study between two turbulence treatments, Reynolds-Averaged Navier-Stokes (RANS) and Large Eddy Simulation (LES), in conjunction with a Conditional Moment Closure (CMC) combustion model over the split injection of "Spray A" conditions from the Engine Combustion Network (ECN) showed promising potential for modeling spray transient processes [4]. The study suggests that LES may be necessary to fully capture combustion recession in a diesel like split injection condition. Studies show that the Yao et al. [34] mechanism with 54 species and 268 reactions (referred to as the Yao mechanism) is capable of qualitatively simulating combustion recession. Jarrahbashi et al. [15] compared two skeletal chemical mechanisms on modeling combustion recession where the Cai et al. [6] mechanism with 57 species and 197 reactions (referred to as the Cai mechanism) was shown to be capable of capturing EOI transients under standard "Spray A" conditions. The Yao mechanism failed to predict 
combustion recession under the same conditions. Studies have also explored the impact of ramp-down shape and duration of the EOI transients on combustion recession. Kim et al. [16] discussed the differences between the Well Stirred Model (WSR) and the Representative Iterative Flamelet (RIF) model in characterizing combustion recession, where it was found that the RIF model better predicted the qualitative observations from experiments. A recent study from the current authors [12], explored the capability of a Flamelet Generated Manifold (FGM) model in predicting combustion recession, where different ambient temperature conditions and two chemical mechanisms (Yao and Cai) were studied. The results favored the newly implemented FGM over the RIF model and the WSR model in terms of the predictions of flame lift-off length and its capability to predict combustion recession using two different chemical mechanisms. Although these studies have come to the same conclusions concerning the influence of ambient thermodynamic conditions on the prediction of combustion recession, discrepancies were found in the capabilities of different chemical kinetic models. Therefore, this study aims to elucidate further the effects of different chemical mechanisms for n-dodecane-including the reduced chemical mechanism from Ranzi et al. [27] (130 species and 2395 reactions referred to as to the Polimi mechanism)-in the prediction of combustion recession.

In the following work, standard "Spray A" conditions from ECN will be investigated under a RANS framework. Firstly, the non-reactive liquid and vapor penetration as well as mixing properties will be analyzed. Four different chemical mechanisms for n-dodecane that are commonly used in the engine simulation communities will be employed to study the influence of chemical mechanisms on combustion recession. These chemical mechanisms will be investigated using a 1D flame solver first to understand their characteristics, peculiarities and reliabilities under diesel engine conditions. Multidimensional reactive spray simulations will then be performed using both an FGM model based on the homogeneous reactor tabulation method and a newly implemented FGM model based on the igniting counterflow diffusion flame tabulation method using the CONVERGE CFD solver. A description of the computed flamelet database will be included together with an analysis comparing the results of the simulations to experimental data from the literature. The effect of tabulation method on reactive spray prediction will be detailed. Finally, the efficacy in predicting combustion recession by each chemical mechanism under an FGM framework will be discussed.

\section{Methods}

\section{Spray Modeling}

A conventional "Blob" injection model is employed to simulate the spray injection process where "parcels" are injected into the computational domain with the same characteristic size as the nozzle diameter. Droplet breakup and atomization are modeled using the Kelvin-Helmholtz Rayleigh-Taylor (KH-RT) model. The inherent grid sensitivity of the KH-RT model has been studied previously for the non-reacting "Spray A" conditions and validated against another commercial CFD solver [23]. Droplet collision is described using the No Time Counter (NTC) model and the droplet drag is accounted for using the dynamic drag model. The evaporation process is modeled using the Frossling correlation. The effects of turbulence on droplets is characterized using the stochastic dispersion model, where turbulence is modelled using the standard $k-\varepsilon$ model with modified constants. Detailed model constants and boundary conditions set up can be found in our previous studies [12].

\section{Combustion Modeling}

In this study, two different Flamelet Generated Manifold (FGM) model based approaches are used for spray combustion simulations. FGM models are based on flamelet concepts and reduced chemistry models, where chemistry calculation is decoupled from the turbulent flow field [24]. The turbulent flame structure is described in FGM models by pre-tabulating one-dimensional flamelets using a reduced number of controlling variables. The representative flamelet solutions are then mapped onto a low-dimensional manifold in composition space to decouple the chemistry calculation. The attractiveness of FGM models is their ability to incorporate detailed chemistry with reduced computational cost. For this study, the 1D laminar flamelet equations given by Stahl and Warnatz [31] are solved:

$$
\begin{gathered}
\frac{\partial \rho}{\partial t}+\frac{\partial}{\partial x}(\rho u)=-\rho K \\
\frac{\partial \rho Y_{i}}{\partial t}+\frac{\partial \rho u Y_{i}}{\partial x}=\frac{\partial}{\partial x}\left(\rho D \frac{\partial Y_{i}}{\partial x}\right)+\dot{\omega}_{i}-\rho K Y_{i} \\
\frac{\partial \rho h}{\partial t}+\frac{\partial \rho u h}{\partial x}=\frac{\partial}{\partial x}\left(\frac{\lambda}{c_{p}} \frac{\partial h}{\partial x}\right)-\rho K h \\
\rho \frac{\partial K}{\partial t}+\rho u \frac{\partial K}{\partial x}=\frac{\partial}{\partial x}\left(\mu \frac{\partial K}{\partial x}\right)+\rho_{o x} a^{2}-\rho K^{2}
\end{gathered}
$$

where $K(x, t)=\frac{\partial u_{y}}{\partial y}$, is the strain rate or flame stretch field, which is a function of the $x$ coordinate and the applied strain rate $a$ at the oxidizer boundary. $D$ is the diffusion coefficient defined as $D=\frac{\lambda}{\rho c_{p}}$. For non-premixed flames a unity Lewis number is assumed in order to simplify the transport equations.

Two types of representative flamelets for non-premixed combustion are compared to study the influence of chemical mechanisms in predicting combustion recession. The first flamelet type is based on 0D ignition flamelets, where the flamelet manifold is obtained by solving an experimental homogeneous reactor (HR). A homogeneous reactor is a simplified zero-dimensional configuration in which the mixture is considered stagnant and perfectly mixed. The governing equations for the HR flamelet can be derived through eliminating the variables associated with the $x$-coordinate, $K$, and $a$ from equations $(1-4)$. The HR flamelet solution is calculated through the CONVERGE CFD OD solver with a tabulation against mixture fraction, $Z$, and a reaction progress variable, $c$. In this study the definition of $Z$ follows the well 
known Bilger correlation [3]. The reaction progress is a monotonic variable that captures each stage of combustion evolution, which is defined as a linear combination of three key species $\left(\mathrm{CH}_{2} \mathrm{O}, \mathrm{CO}\right.$ and $\left.\mathrm{CO}_{2}\right)$ normalized by their equilibrium value. The inclusion of $\mathrm{CH}_{2} \mathrm{O}$ is inspired by the notion that it is significant at the start of the ignition process, whereas $\mathrm{CO}$ represents the intermediate stage of combustion and subsequently $\mathrm{CO}_{2}$ represents the end of combustion process. It is to be noted here that the definition of progress variable will not affect results as long as the chemistry parametrization (selection of species) represents each stage of chemistry evolution and is monotonic. The monotonicity of the progress variable is ensured during the parametrization process leading to a consistent FGM. A detailed description for the implementation can be found in [1].

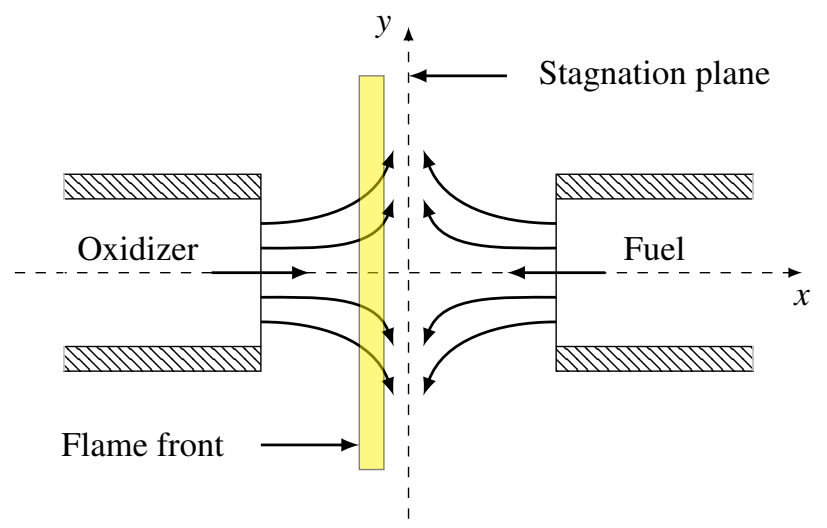

Figure 1. Schematic of laminar non-premixed counterflow diffusion flame

The second type of flamelet studied herein is the 1D non-premixed laminar counterflow diffusion flame (CDF) where solutions are computed in physical space and time using the CHEM1D code [7]. The CDF tabulation method makes fundamentally different assumptions compared to the HR tabulation method whereby diffusion and transport processes are considered to have a minor role during ignition. The experimental set up of the CDF is depicted in Figure 1. For a stationary $\mathrm{CDF}$, the manifold is generated using a sequence of steady flames solutions with strain rates varying from the lowest value to the quenching value. However, as spray simulations are unsteady and initially non-reacting, time-dependent flamelets are solved from a mixed but non-reacting initial state in order to capture transient events in diesel sprays. The ignition behavior is followed in time until a steady state flame is reached. Previous studies have shown that generating unsteady flamelets using quenching flamelets does not lead to ignition of diesel sprays. Therefore, for this study the FGM is constructed using the igniting counterflow diffusion flame (ICDF) flamelet solution.

Complete generation of the manifold follows solving a transient counterflow diffusion flame at a strain rate of $500 \mathrm{~s}^{-1}$ from an initially mixed, but non-reacting state first and then tracking this flame through ignition up until quasi-steady state (QSS). Steady state flamelets are then computed from $500 \mathrm{~s}^{-1}$ down to $1 \mathrm{~s}^{-1}$ to complete the manifold close to chemical equilibrium. Applied strain rate of $500 \mathrm{~s}^{-1}$ has been determined by Wehfritz et al. as the highest non-quenching strain rate for ECN "Spray A" conditions [32]. Studies showed ignition delay times to be

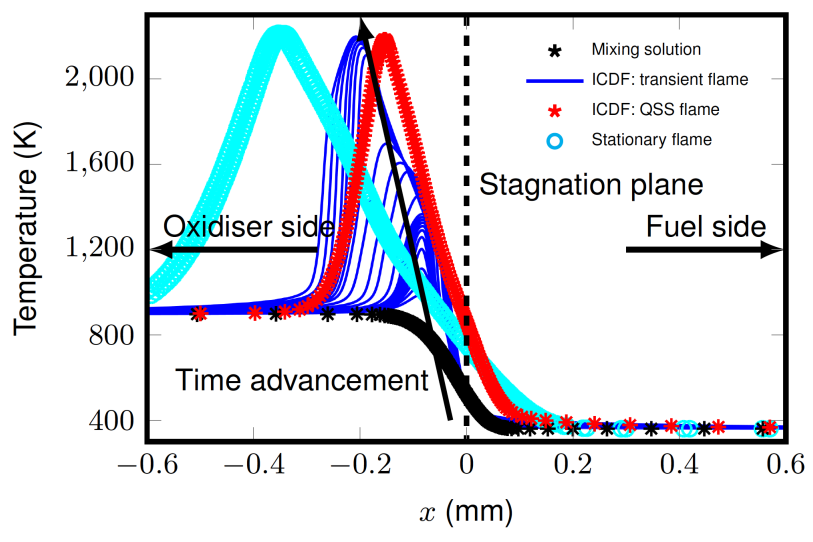

Figure 2. Temperature evolution $T(x, t)$ obtained for under $900 \mathrm{k}$ reacting "Spray A" conditions

insensitive to strain rates less than $1000 \mathrm{~s}^{-1}$. Bekdemir et al. [2] also found that for moderately strained configurations, a single ICDF flamelet was able to adequately capture the ignition process. An example of temperature evolution as a function of space and time can be found in Figure 2.

Once the flamelet solutions are obtained, they are tabulated as a function of mixture fraction and reaction progress variable with a manifold resolution of 100x100 quadratically spaced points respectively. Quadratic spacing provides refinement near stoichiometry, ensuring interpolation accuracy during the early phases of ignition as described by Eguz et al. [11]. A sample resultant manifold in $Z-c$ space can be seen in Figure 3. Coupling of the FGM database with the CONVERGE flow solver is achieved via a representative set of species mass fractions and the chemical source term of the reaction progress variable, $c$. For this study, 15 representative species are considered for each respective chemical mechanism. The retrieval of the chemical properties from the FGM is achieved via linear interpolation. A schematic of FGM and turbulent flow field coupling can be found in Figure 4.

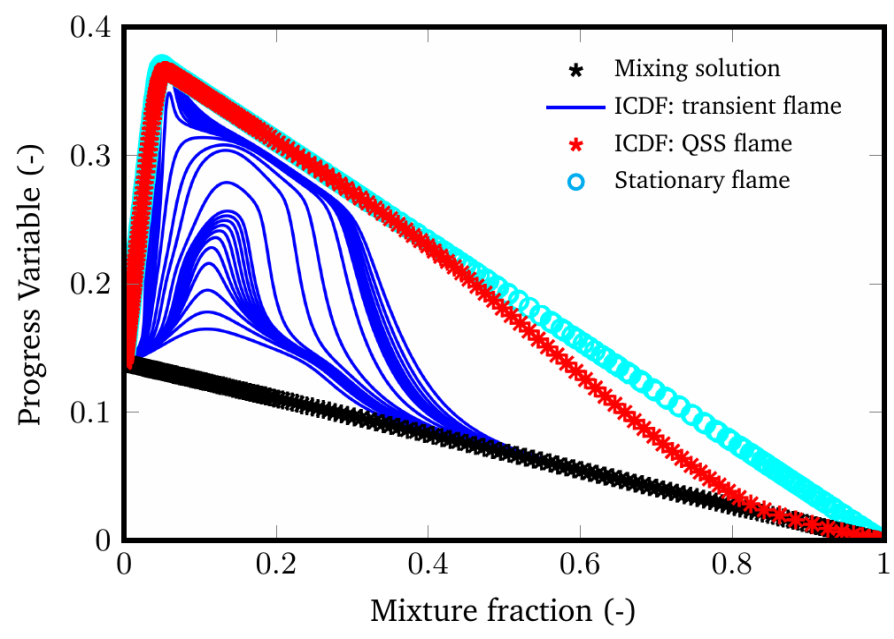

Figure 3. Flamelet solutions in progress variable-mixture fraction space for a counterflow diffusion flame under "Spray A" conditions 


\begin{tabular}{|c|c|c|}
\hline $\begin{array}{l}\text { CONVERGE CFD } \\
\text { Solver } \\
\cdot \text { Continuity } \\
\cdot \text { Momentum }\end{array}$ & & $\begin{array}{c}\text { Flamelets Solver } \\
\text { 1D Laminar } \\
\text { Flamelets } \\
\text { (HR/ICDF) }\end{array}$ \\
\hline $\begin{array}{l}\cdot \text { Turbulence } \\
\cdot \text { Energy }\end{array}$ & & $x, t$ to $Z, c$ \\
\hline $\begin{array}{l}\text { - Progress Variable } \\
\text { - Mixture fraction }\end{array}$ & $\dot{\omega}(Z, c)$ & $\begin{array}{l}\text { Tabulation } \\
f(Z, c)\end{array}$ \\
\hline
\end{tabular}

Figure 4. FGM combustion model coupling with CONVERGE CFD solver

\section{Case Setup}

\section{ECN “Spray A”}

Simulations are performed for the ECN "Spray A" and the results are validated against the ECN's high-quality and high-fidelity data-sets. "Spray A" is a low-temperature combustion condition relevant to engines that use moderate EGR and have minimal NOx emissions. The injector specifications pertain to modern advanced injection systems with high pressure capability. Both non-reacting and reacting conditions for "Spray A" tested in this study are listed in Table 1.

Table 1. "Spray A" Nominal Boundary Conditions

\begin{tabular}{|l|c|l|}
\hline Test Type & Non-reacting & Reacting \\
\hline Fuel surrogate & \multicolumn{2}{|c|}{ n-dodecane } \\
\hline $\mathrm{P}_{\text {Injection }}($ bar $)$ & \multicolumn{2}{|c|}{1500} \\
\hline $\mathrm{P}_{\text {Ambient }}($ bar $)$ & \multicolumn{2}{|c|}{60} \\
\hline $\mathrm{T}_{\text {Fuel }}(\mathrm{K})$ & \multicolumn{2}{|c|}{363} \\
\hline $\mathrm{T}_{\text {Ambient }}(\mathrm{K})$ & \multicolumn{2}{|c|}{900} \\
\hline Nozzle Diameter $(\mu \mathrm{m})$ & \multicolumn{2}{|c|}{90} \\
\hline Injection Duration $(\mathrm{ms})$ & \multicolumn{2}{|c|}{1.5} \\
\hline Injection Mass (mg) & 3.5 \\
\hline Ambient Gas Composi- & $0 \% \mathrm{O}_{2}$ & $15 \% \mathrm{O}_{2}$ \\
tion [by vol.] & $89.71 \% \mathrm{~N}_{2}$ & $75.15 \% \mathrm{~N}_{2}$ \\
& $3.77 \% \mathrm{H}_{2} \mathrm{O}$ & $3.62 \% \mathrm{H}_{2} \mathrm{O}$ \\
& $6.52 \% \mathrm{CO}_{2}$ & $3.62 \% \mathrm{CO}_{2}$ \\
\hline
\end{tabular}

All simulations are conducted using the commercially-available CFD solver, CONVERGE. CONVERGE is a general purpose $\mathrm{CDF}$ code for computing three dimensional incompressible or compressible chemically-reacting fluid flows. The computational domain is set to be the same as the Sandia combustion chamber, a cube with edge length of $108 \mathrm{~mm}$. The base grid size is set at $1 \mathrm{~mm}$ with Adaptive mesh refinement (AMR) of $0.25 \mathrm{~mm}$ applied to all simulations to refine regions of interest and reduce the computational cost. For non-reacting cases, AMR is applied to the velocity field, and in reacting cases, AMR is applied to both velocity and temperature fields. The AMR triggering parameters are set at $0.1 \mathrm{~ms}^{-1}$ for the sub-grid velocity fluctuations and $2.5 \mathrm{~K}$ for the sub-grid temperature field fluctuations. Fixed grid embedding of size $0.25 \mathrm{~mm}$ is also applied to a small volume near the nozzle exit to increase grid resolution in this high velocity region. The chosen grid sizes are based on previous grid convergence tests and is consistent with other studies conducted under the CONVERGE solver framework. A sample AMR grid can be seen in Figure 5. In the present study a second order accurate spatial finite volume discretization scheme is employed for the governing equations. The transport equations are solved using the pressure implicit with splitting of operators (PISO) method. A variable timestep with a minimum of $10^{-8} \mathrm{~s}$ is used for all simulations. Studies have shown spray penetration in near nozzle regions depends heavily on rate of injection (ROI) characteristics, therefore, instead of using the measured ROI profile for "Spray A", a modified profile from ECN database which accounts for noise and vibration is used [12]. The modified rate of injection profile can be see in Figure 6.

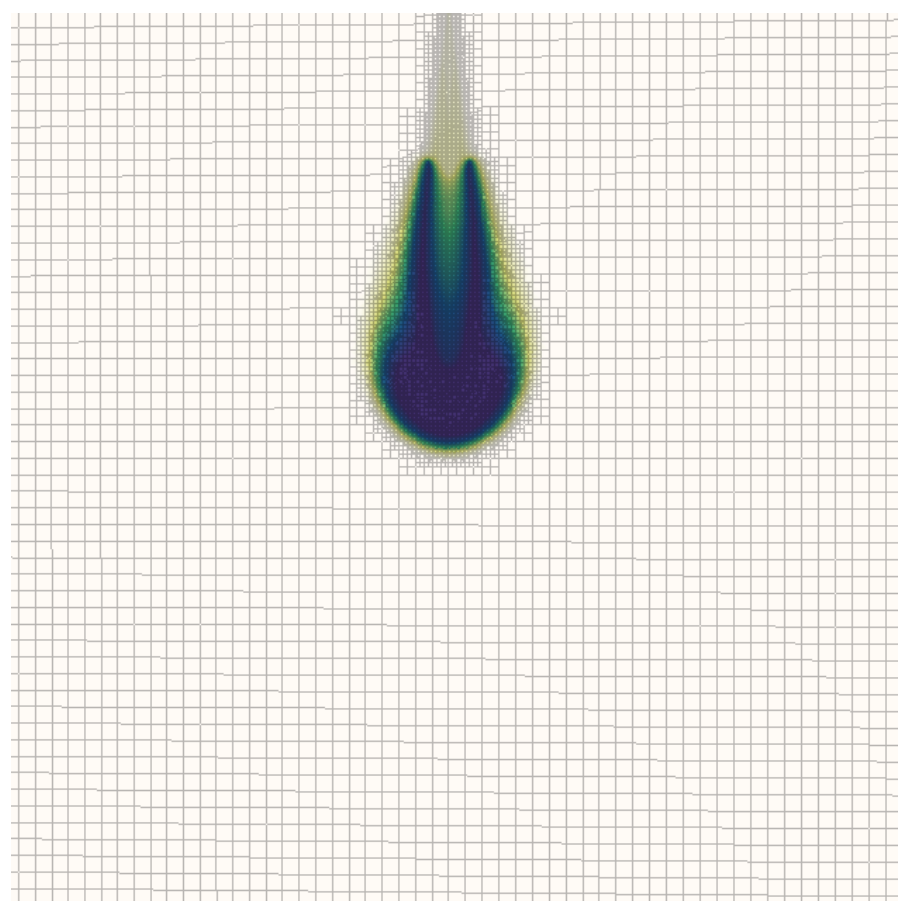

Figure 5. Computational domain showing AMR.

\section{Flamelet Solutions Study}

This section presents a comparative study of the combustion mechanisms' behavior in 1D, i.e. the fundamental behaviour of the mechanisms removed from the spray environment (essentially considering the top right-hand box in Figure 4 in isolation). Note that all flamelet solutions within this section are computed using the one-dimensional flame code - CHEM1D, and that only flamelet solutions generated from the ICDF approach are investigated.

The four different chemical mechanisms for $\mathrm{n}$-dodecane that are investigated are listed in Table 2. All mechanisms are 
Table 3. Ignition delay time from the unsteady flamelet calculations

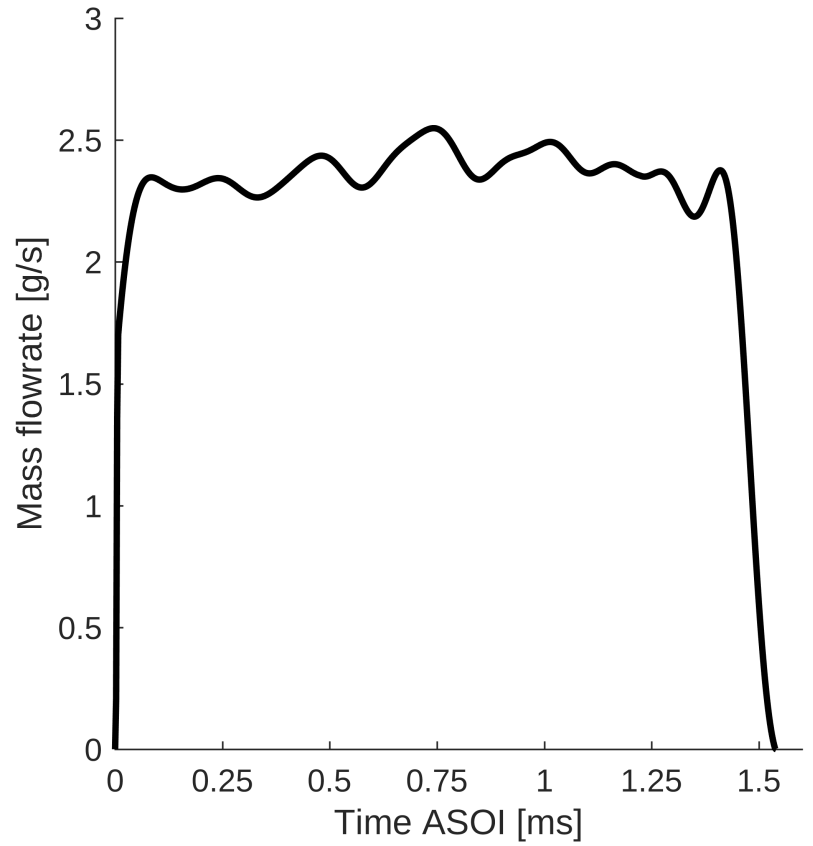

Figure 6. Rate of injection used in CFD simulations.

derived from detailed mechanisms with thousands of species and reactions. The differences between each mechanism comes from its initial mechanism and reduction methodology. All these mechanisms have been validated and developed with accuracy targeting engine related conditions. It is worth noting that the Yao mechanism, though very compact, is specifically tuned for "Spray A" conditions [34].

Table 2. Baseline combustion model comparison

\begin{tabular}{|l|l|l|l|}
\hline Mechanism & $\begin{array}{l}\text { Number } \\
\text { of species }\end{array}$ & $\begin{array}{l}\text { Number of } \\
\text { reactions }\end{array}$ & $\begin{array}{l}\text { Original } \\
\text { mechanism }\end{array}$ \\
\hline Cai et al. [6] & 57 & 197 & {$[33]$} \\
\hline Yao et al. [34] & 54 & 268 & {$[35]$} \\
\hline Luo et al. [22] & 105 & 420 & {$[33]$} \\
\hline Ranzi et al. [27] & 130 & 2395 & {$[28]$} \\
\hline
\end{tabular}

Figure 7 shows the maximum temperature evolution of the unsteady flamelet solutions under the reacting "Spray A" baseline conditions for all four chemical mechanisms. All chemical mechanisms are able to capture different stages of combustion. Stage 1 of combustion initiated by the premixed spray region low temperature heat release is well represented by the Cai, Luo and Polimi mechanisms at around $0.3 \mathrm{~ms}$ ASOI, whereas the Yao mechanism predicts early first stage combustion. Stage 2 of combustion is seen as a steep temperature rise after stage 1 . Stage 2 is observed at around 0.4 ms ASOI for both the Cai and Polimi mechanisms, whereas the Luo mechanism prolonged the respective time to about $0.5 \mathrm{~ms}$

\begin{tabular}{|l|c|c|c|c|c|}
\hline Mechanisms & Cai & Yao & Luo & Polimi & Experiment \\
\hline IDT (ms) & 0.394 & 0.285 & 0.599 & 0.323 & 0.45 \\
\hline
\end{tabular}

ASOI. The Yao mechanism is seen to give an earlier second stage combustion at around $0.25 \mathrm{~ms}$ ASOI. A more quantitative study of ignition delay time (IDT) using the definition from the ECN is shown in Table 3. According to the recommended ECN guidelines, ignition delay time is calculated as follows:

$$
\tau_{I D T}=\tau\left(\max \left(\frac{d T_{\max }}{d t}\right)\right)-\tau_{S O I}
$$

The early ignition prediction by the Yao mechanism has been attributed to increased accumulation of $\mathrm{HO} 2$ which is a key species in tracking first stage ignition [8]. It was found by [9] that reactions producing $\mathrm{HCO}$ which is a key species in producing $\mathrm{HO} 2$ were enhanced in the Yao mechanism leading to early ignition delay predictions. Additionally, predictions of the high temperature ignition stage which is promoted by the species $\mathrm{H} 2 \mathrm{O} 2$ are also early for the Yao mechanism, as reactions relevant to the production of $\mathrm{H} 2 \mathrm{O} 2$ are highly enhanced in the Yao mechanism compared to the other mechanisms. The differences between the chemical mechanisms are further studied through the chemical source term of the progress variable $\dot{\omega}_{c}$ for each mechanism. The source term of the progress variable has a significant effect in the predictions of combustion and ignition delay time. All chemical mechanisms generate three well defined reaction zones representing the different stages of combustion with lower regions depicting the early ignition stage species $\left(\mathrm{CH}_{2} \mathrm{O}\right)$, intermediate regions representing intermediate stage of combustion species $(\mathrm{CO})$ and top regions representing the end of combustion species $\left(\mathrm{CO}_{2}\right)$. Figure 8 gives significant prior insight into the expected behaviour of each mechanism before embarking on the detailed 3-D RANS simulations of the reacting spray. As expected from the temperature evolution and ignition delay study, the Yao mechanism clearly shows much higher values of chemical source term in low progress variable regions, representing the ignition stage of combustion, than the other mechanisms. The Luo mechanism shows a relatively lower source term values in regions associated with ignition and the intermediate stages of combustion stages which corresponds to the prolonged temperature rise in flamelet solutions. The Polimi mechanism and the Cai mechanism present similar magnitudes in all three regions with the Cai mechanism having higher source term values in the intermediate region and the Polimi mechanism having higher source term values in the ignition region.

\section{Results and Discussions - 3D Spray Simulations}

\section{Non-reacting Case}

Following the same validation procedures as previous works from the authors, the non-reacting evaporating "Spray A" condition was first validated against the ECN experimental data for liquid and vapor penetration. Details of the authors' grid 


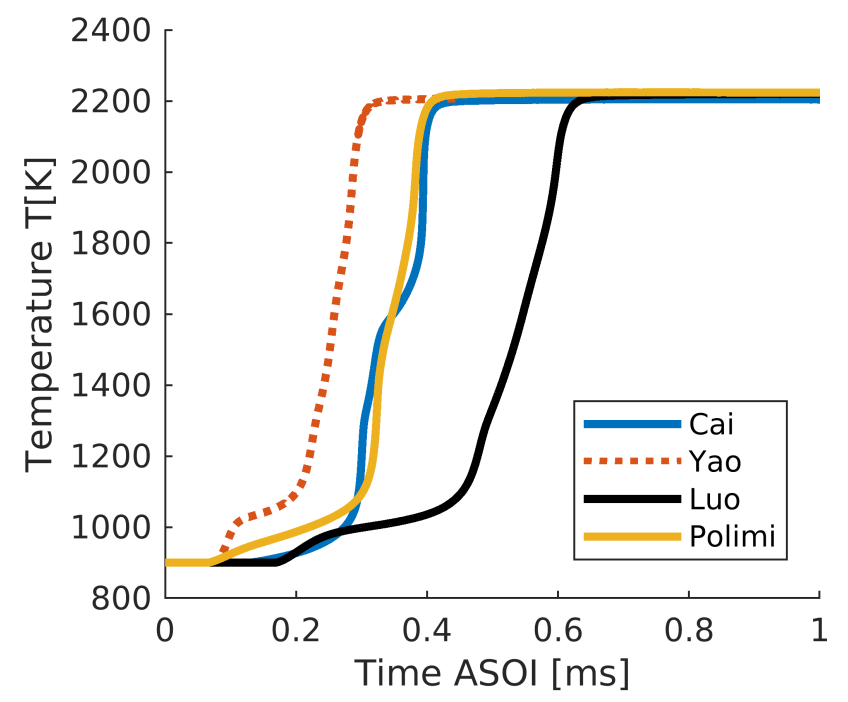

Figure 7. Maximum temperature evolution for 1D Igniting Counterflow Diffusion flame simulations at the reacting "Spray A" baseline conditions for all mechanisms: $\mathrm{T}_{\text {ambient }}=900, \mathrm{~K} 15 \% \mathrm{O}_{2}$.

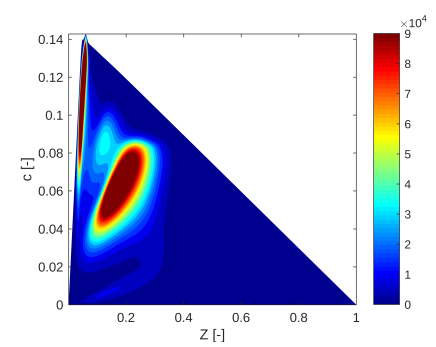

(a) Cai

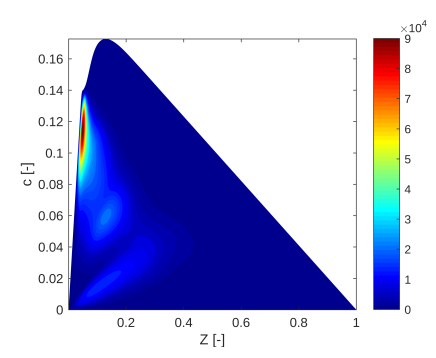

(c) Luo

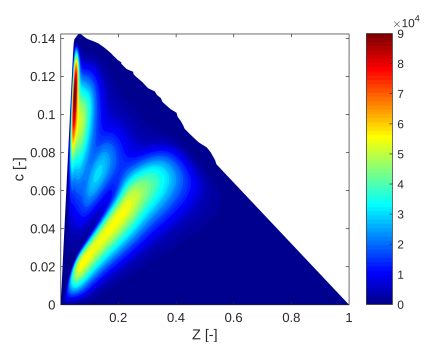

(b) Yao

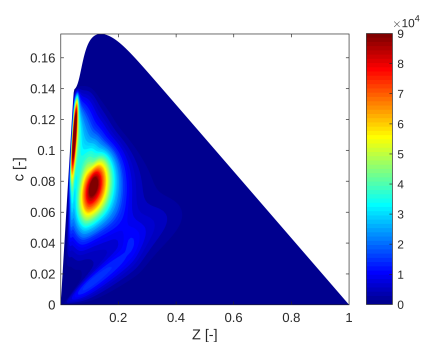

(d) Polimi
Figure 8. $900 \mathrm{~K}$ reacting case chemical source term of the progress variable with different mechanisms.

dependency and physical sub-model testing can be found in [23]. Following the ECN guidelines, the liquid spray penetration is defined as the axial distance encompassing $97 \%$ of injected fuel mass and the vapor penetration is defined as the maximum distance from the injector to where the fuel mass fraction reaches $0.1 \%$. Figure 9 shows the liquid and vapor penetrations compared to ECN experimental data. The simulated results agree well with the experimental data both in initial transient and steady-state periods. Figure 10 shows the mean radial mixture fraction profiles at two axial locations compared to the experimental data. The profiles are slightly underpredicted around the liquid core for both locations, but still lie within the bounds of experimental uncertainty.

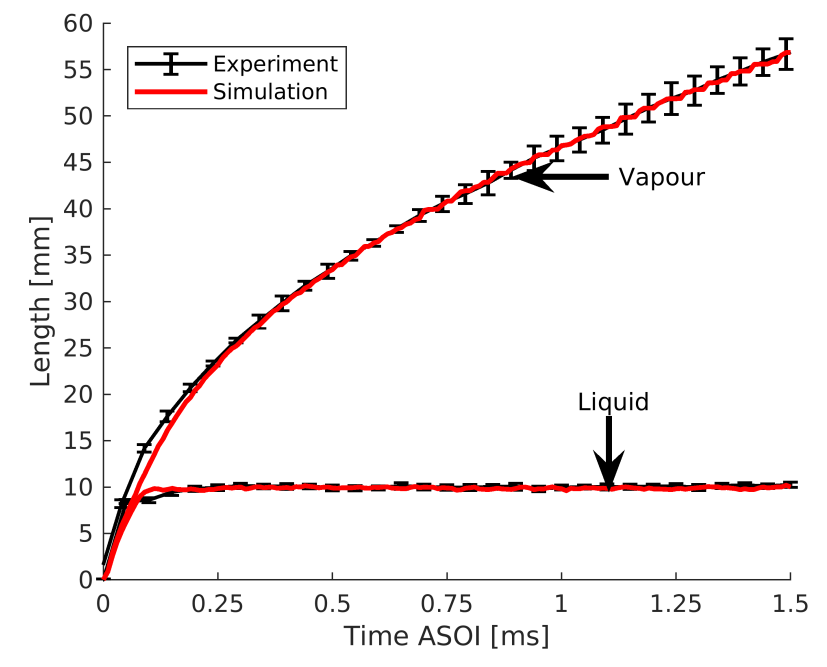

Figure 9. Non-reacting liquid and vapor penetration for "Spray A" baseline conditions

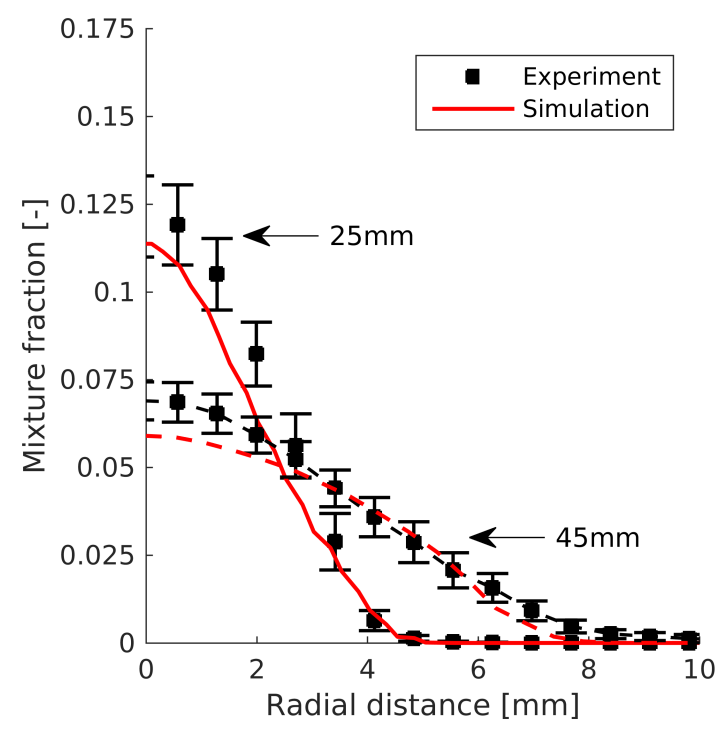

Figure 10. Mixture fraction radial profile for non-reacting "Spray A" baseline case at two axial downstream locations

\section{Reacting Spray Simulations}

Reacting spray simulations were performed under the conditions outlined in Table 1. Two canonical combustion configurations representing the spray flame chemical processes were used: homogeneous reactor (HR) and igniting counterflow diffusion flame (ICDF). Firstly, the predictions from an HR based FGM (referred to as the 0D FGM) model are compared with those of an ICDF based FGM (referred to as the 1D FGM) model to show the relative performances of the two FGM methods based on a comparison of ignition delay time, lift off length and EOI combustion recession. This comparative study is followed by an investigation into the performance of the different chemical mechanisms using the best performing FGM model. 
As previously discussed, the generation of the 0D FGM manifold is achieved by using a homogeneous reactor assumption solved within the CONVERGE software. Figure 11 shows the maximum temperature evolution of both OD and 1D FGM simulations under the "Spray A" conditions for the Cai mechanism. As seen from the figure, the two stages of combustion were captured by both approaches. However, the OD FGM model predicts ignition much earlier than 1D FGM case and remains at a much higher temperature at all times throughout the simulation. The predicted ignition delay is then shorter for the OD FGM than for the 1D FGM case. The findings obtained in this study are then very similar to the study that was performed by Eguz et al. [11] where the HR FGM is found to give shorter ignition delay times for ECN "Spray $\mathrm{H}$ ".

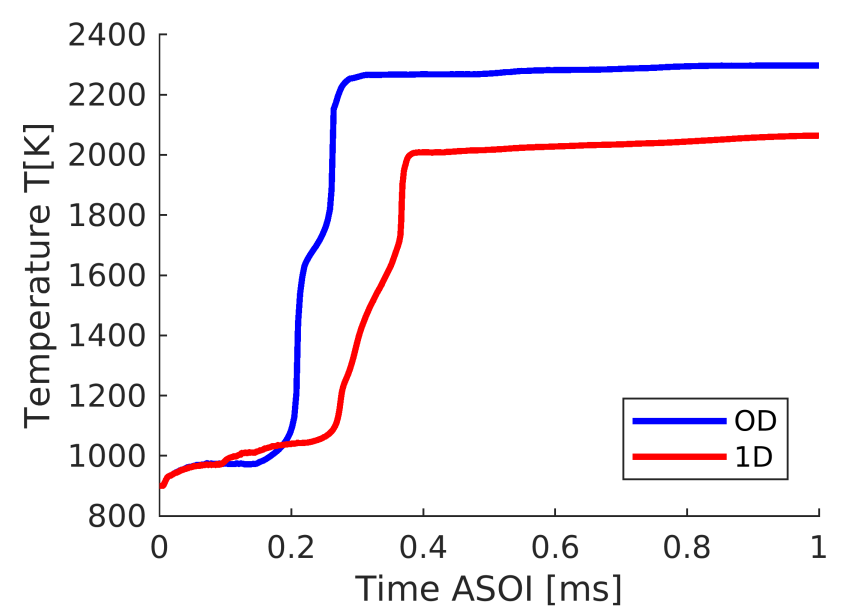

Figure 11. "Spray A " baseline conditions time evolution of maximum temperature with HR based OD FGM and ICDF based 1D FGM for the Cai chemical mechanism

In order to further study the differences between two FGM approaches, the flame lift-off length and combustion recession characteristics are investigated. The definition of LOL used in this work is consistent with the ECN standard for simulations and is thus defined as the distance from the injector to the first location where the Favre-averaged $\mathrm{OH}$ mass fraction reaches $14 \%$ of the instantaneous maximum during the steady state period. Figure 12 shows the temperature contours of both FGM approaches at two different timesteps. It is clear that the LOL for the $0 \mathrm{D} F G M$ case $(\mathrm{LOL}=12.84 \mathrm{~mm}$ ) is much shorter than that predicted by the $1 \mathrm{D}$ FGM case $(\mathrm{LOL}=18.34 \mathrm{~mm}$ ), which follows the same trend of IDT observations discussed earlier. A similar trend was also found by Eguz et al. [10] while studying tabulation methods for "Spray A" where LOL is found to have an almost linear correlation with the IDT. The reasons for this can be explained by the higher production of the progress variable in the near nozzle region caused by early ignition in the 0D FGM.

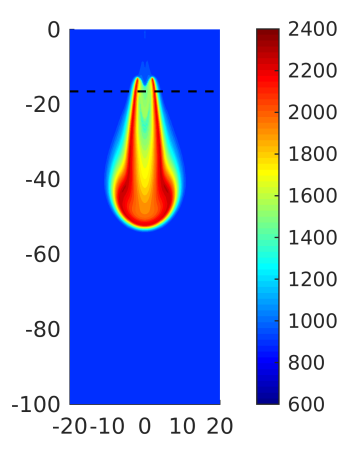

(a) 0D

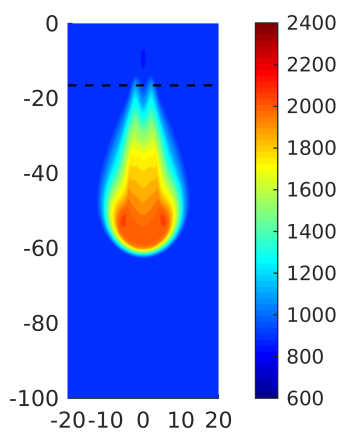

(c) $0 \mathrm{D}$

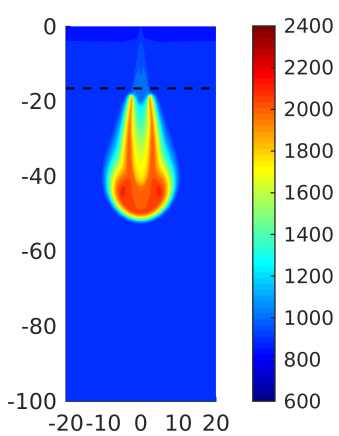

(b) $1 \mathrm{D}$

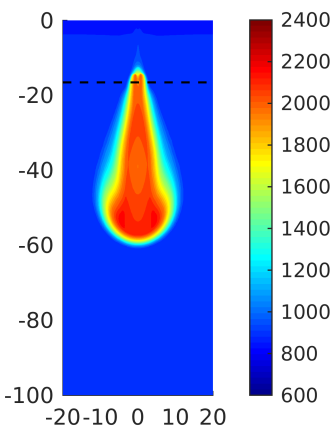

(d) $1 \mathrm{D}$
Figure 12. "Spray A" baseline conditions with the Cai mechanism with temperature distribution. (a) (b) $1.3 \mathrm{~ms}$ (c)(d) $1.8 \mathrm{~ms}$. Black line: measured lift-off length from ECN database

More importantly and to the great interest of this present study, combustion recession was not captured by the OD FGM whereas clear flame retraction after end of injection is observed in the 1D FGM results as shown in Figure 12. This can be explained by the HR tabulation method's exclusion of diffusion and transport phenomenon. Owing to this fundamental difference between the HR and ICDF tabulation methods, the HR tabulation is found to have higher source term values across all regions of progress variable and mixture fraction space[24]. Therefore, higher temperatures and less radially extended flame regions are found in OD FGM results, which align with the discussions earlier in terms of shorter IDT and LOL. Combustion recession was not captured by 0D FGM despite the higher chemical source term presented in HR tabulation. This is likely due to the nature of HR tabulation where the influence of strain effects on diffusion flame is not included. In addition with a narrower reaction zone, a higher axial velocity is found upstream of the LOL which reduces the residence time for fuel mixtures that otherwise could reach second stage ignition and hence promote combustion recession [14]. Based on the findings presented in this section, while the HR based FGM approach is capable of capturing both IDT and LOL with good accuracy, the ICDF based FGM is necessary to capture the end of injection processes due to it's better representation of strain effects and transport phenomenon in diffusion flames. 
Therefore, the following studies on the effect of chemical mechanisms in predicting combustion recession will be constructed using the 1D FGM approach.

\section{Effect of Chemical Mechanisms on 1D FGM RANS Simula- tions of ECN "Spray A"}

The differences in chemical mechanisms are first visualized through the maximum temperature evolution from 1D FGM simulations shown in Figure 13. As expected, the trend of the temperature evolution follows the same result as 1D flamelet solutions where the Yao mechanism reaches both stages of combustion earliest and the Luo mechanism shows retarded combustion. The maximum temperature for all mechanisms are brought down to around $2000 \mathrm{~K}$ which is consistent with other flamelet based model simulations [20]. The lower temperature compared to 1D simulation can be seen as a result of a RANS averaging calculation in terms of mixture fraction and progress variable, which results in a lower source term value during the look-up process. Previous studies have also shown lower temperature contours from RANS turbulence treatment compared to LES [26].

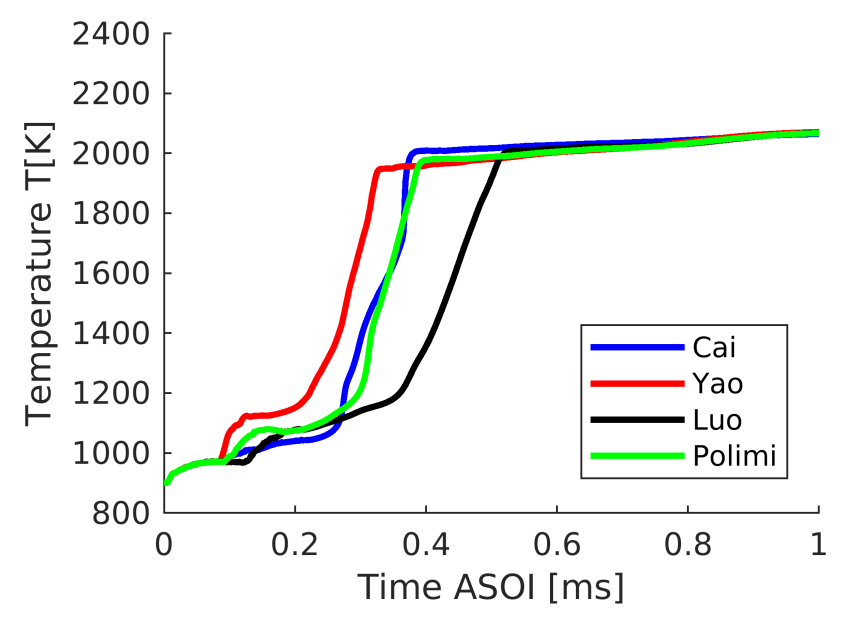

Figure 13. "Spray A" baseline conditions time evolution of maximum temperature from 1D FGM using different chemical mechanisms

A more quantitative study of IDT and LOL using the definitions outlined previously are shown in Table 4. The Yao mechanism predicted a shorter ignition delay time which is consistent with other studies with the reason for this underprediction stemming from the higher reactiveness of the Yao mechanism in the manifold's ignition region. The Polimi mechanism IDT prediction, although shorter compared to experimental data, is consistent with the LES study performed by Wehrfirtz et al. [32]. Similar results for the Luo and Cai mechanism IDT predictions can also be found in previous studies [27] [16]. The IDT results from RANS simulations also indicate that IDT predictions are mainly driven by the ignition behavior of chemical mechanisms since the 3D simulations have limited effect on the predictions of IDT. The clear resemblance of IDT predictions between the RANS study and the flamelet solutions study shows the dominant role of the chemical mechanism in spray autoignition predictions. In terms of LOL, both Cai and Yao mechanisms are able to predict these combustion indicators, whereas Luo and Polimi mechanisms showed a longer LOL. This finding is consistent with earlier flamelet solutions where LOL showed a linear correlation with IDT. It is also worth noting that the experimental LOL in the ECN database is defined using a threshold of $50 \%$ of chemiluminescence leveling-off value, while numerically there are different ways to quantify LOL. Therefore, the quantitative assessment in this study will serve as the guidance for physical trends. Overall, all chemical mechanisms were able to predict both quantities at values close to the experimental data under a RANS FGM framework.

Table 4. "Spray A" baseline conditions ignition delay time and flame liftoff length from 1D FGM simulations compared to ECN Sandia experimental measurements.

\begin{tabular}{|l|c|c|c|c|c|}
\hline Mechanism & Cai & Yao & Luo & Polimi & Experiment \\
\hline IDT $(\mathrm{ms})$ & 0.3667 & 0.315 & 0.47 & 0.381 & 0.45 \\
\hline LOL $(\mathrm{mm})$ & 18.34 & 16.1 & 25.78 & 21.04 & 16.5 \\
\hline
\end{tabular}

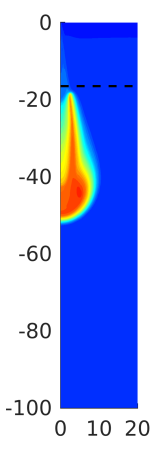

(a) Cai

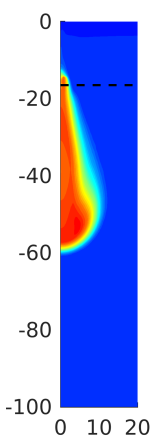

(e) Cai

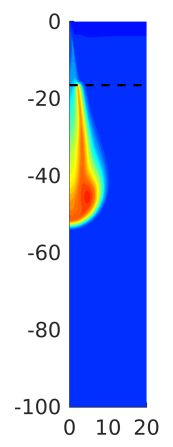

(b) Yao

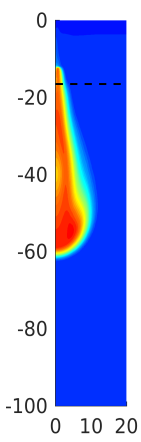

(f) Yao

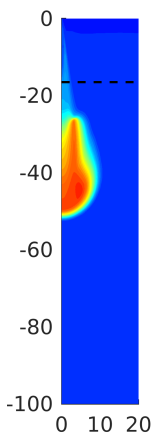

(c) Luo

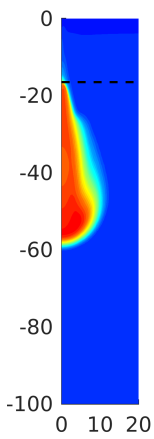

(g) Luo

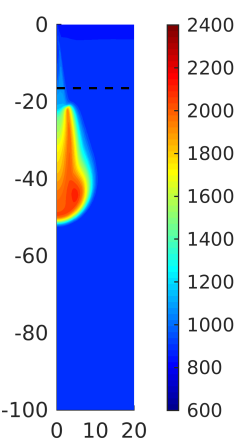

(d) Polimi
Figure 14. "Spray A" baseline conditions temperature distributions for all mechanisms. (a) (b) (c) (d): $1.3 \mathrm{~ms}$ ASOI (e) (f) (g) (h): $1.8 \mathrm{~ms}$ ASOI. Black line: measured lift-off length from ECN database

In order to help visualize the performance of the different chemical mechanisms in predicting LOL, reactive spray penetration and combustion recession, Figure 14 shows the simulated temperature contour from 1D FGM for all mechanisms under "Spray A" baseline conditions. At quasi-steady state $(1.3 \mathrm{~ms})$ some differences are observed in the temperature profiles, however, the overall flame structure is not significantly influenced by the applied chemical mechanisms. The lack of available experimental data also made it difficult to 
compare the recession distance quantitatively. For the 1D FGM approach, lift-off length is located where the large strain rates and higher scalar dissipation rate exceed the flame extinction limit. Therefore, it is highly dependent on the sensitivity of chemical mechanisms in terms of strain rate as well as the local thermodynamics conditions. Only small differences were noticed under "Spray A" baseline conditions with the Luo mechanism giving a higher LOL and slightly varied flame structure. This is due to weaker low temperature reactivity which is consistent with the previous manifold study. It is also worth noting that although originating from the same mechanism, the Luo mechanism and the Cai mechanism exhibit different behavior in terms of flame predictions which again shows the importance of including low temperature chemistry under "Spray A" baseline conditions. Figure 14 also shows the end of injection (1.8 ms ASOI) transient predictions using all four chemical mechanisms. Combustion recession is clearly captured by all mechanisms with all flames retracting back to the nozzle tip passing through the LOL. A further analysis is shown in Figure 15 with the $\mathrm{OH}$ mass fraction plotted along the injector axis. It can be seen the the increase in $\mathrm{OH}$ mass fraction near the nozzle for all chemical mechanisms clearly show that the mixture has reached second-stage ignition indicating combustion recession. The distinct spikes in $\mathrm{OH}$ mass fraction shown for all chemical mechanism, but especially the Cai and the Yao mechanisms, can be seen as separate autoignition pockets upstream of the LOL, which is consistent with the experimental study conducted by Knox et al. [19].Additionally, it can be seen from mixture fraction-temperature space in Figure 16 that the low temperature combustion tracer $\mathrm{CH} 2 \mathrm{O}$ is active for all mechanisms indicative that low temperature reactions are occurring towards the end of injection which will eventually lead to combustion recession. As seen earlier with the axial $\mathrm{OH}$ distribution, the Cai mechanism has a much higher concentration of $\mathrm{CH} 2 \mathrm{O}$ and at much higher temperatures which is consistent with the strong prediction of combustion recession. It can also be seen from Figure 16 that the Yao and Polimi mechanisms have a broader distribution of $\mathrm{CH} 2 \mathrm{O}$ over a range of mixture fractions leading to less pronounced peaks of $\mathrm{OH}$ and weaker prediction of combustion recession compared to the Cai mechanism. More interestingly, the predictions of combustion recession align well with the flamelet solutions where the Cai mechanism showed much higher $\mathrm{OH}$ concentrations when autoignition is established, corresponding to higher chemical source term at intermediate stage combustion. The Yao mechanism retracts further up to the nozzle tip which shows stronger ignition behavior corresponding to a higher source term in igniting regions. The Polimi mechanism showed similar predictions to the Cai mechanism in terms of flame retraction however the $\mathrm{OH}$ concentration is much lower compared to the Cai mechanism. The Luo mechanism again shows lower $\mathrm{OH}$ concentration as well as shorter combustion recession. This further indicates that for the RANS 1D FGM approach low temperature chemistry behavior plays a significant role in both steady state flame structure and end of injection combustion recession predictions. Although capable of predicting combustion recession, the current 1D FGM implementation does not include turbulent chemistry interactions in the manifold, which could explain the flame not travelling all the way to the nozzle tip. We note however, that due to the limited availability of relevant experimental data, the exact flame retraction distance is not well quantified currently. However, the combustion recession predictions here closely agree with previous RANS CMC split injection studies using the Yao mechanism [4] and the well stirred model study using the Cai mechanism [16] under "Spray A " conditions. Particular strength was found for this 1D FGM implementation in the capability of incorporating different chemical mechanisms and the ability to predict combustion recessions.

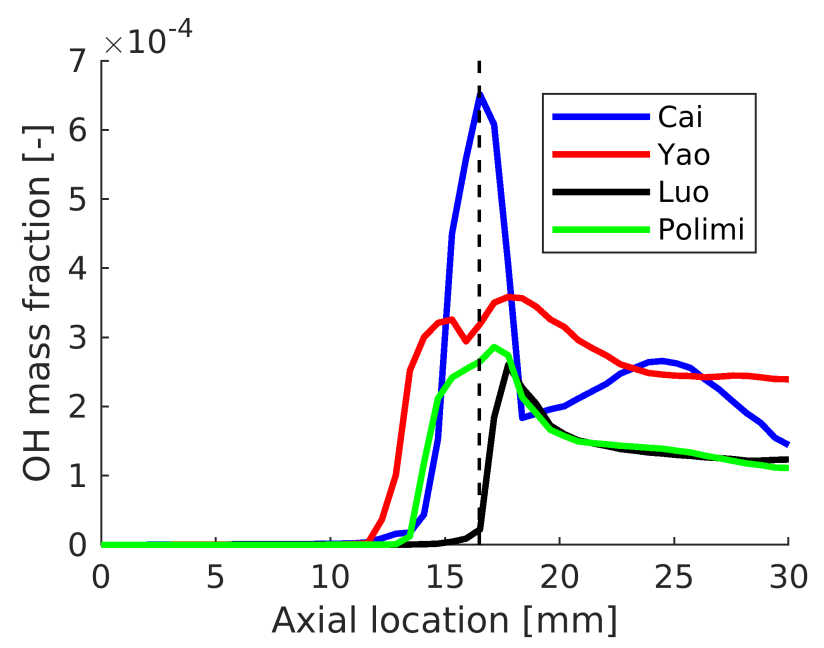

Figure 15. "Spray A" baseline conditions $\mathrm{OH}$ mass fraction comparison from 1D FGM using different chemical mechanisms at $1.8 \mathrm{~ms}$ ASOI. Black line: measured lift-off length from ECN database

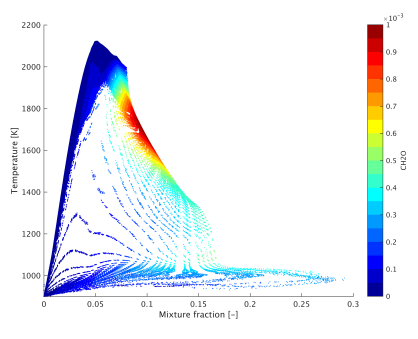

(a) Cai

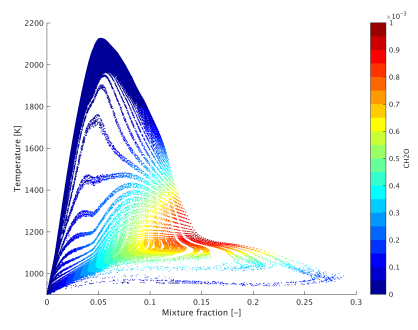

(c) Luo

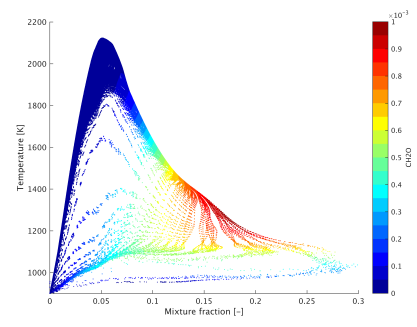

(b) Yao

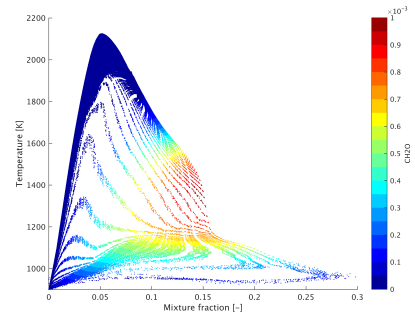

(d) Polimi
Figure 16. "Spray A" baseline conditions scatter point presentation in ZT plane, coloured by $\mathrm{CH}_{2} \mathrm{O}$ at $\mathrm{t}=1.4 \mathrm{~ms}$.

\section{Conclusions}

Three dimensional diesel "Spray A" simulations have been performed in this study under a RANS FGM framework. The objectives of this study include: (1) comparing the ability of 
two different tabulation methods: the 0D igniting homogeneous reactor approach and 1D igniting counterflow diffusion flame approach, under a RANS FGM framework to predict combustion recession, (2) to study the effect of chemical mechanisms in predicting flame structure and combustion recession using the chosen FGM approach. All Simulations were conducted using Eulerian-Lagrangian spray models. Only the baseline conditions of low temperature diesel combustion corresponding to the "Spray A" experiments were tested.

Non-reacting evaporating spray characteristics were validated against experimental results from the ECN database with the chosen spray sub-models showing good agreement for global parameters such as liquid and vapor penetration and also local parameters of radial mixture fraction distribution.

Reactive simulations were carried out using a newly implemented FGM model in CONVERGE with flamelet solutions generated from both CONVERGE and CHEM1D. The study of tabulation method showed that both the HR and the ICDF methods are capable of qualitatively capturing the flame structure at steady-state. However, higher source terms were found for the HR case which leads to shorter ignition delay and LOL than the ICDF approach. Higher temperature contours were also found in the HR approach when compared to the ICDF approach owing to exclusion of diffusion and transport phenomenon during reaction. The lack of strain effects in diffusion flame also resulted in failure of the HR FGM approach to predict combustion recession. This indicates the significant role that diffusion processes still play in flame predictions, and particularly on end of injection processes such as combustion recession, even at the very high temperature and pressure conditions typical of diesel engine combustion. We conclude therefore, that in order to capture end of injection transient phenomenon in diesel sprays, the ICDF tabulation approach for the FGM model is more appropriate.

Three skeletal mechanisms and one reduced chemical mechanism were tabulated using the ICDF approach and 3D reacting simulations were performed under "Spray A" baseline conditions. The diesel spray flame structures predicted by all chemical mechanisms were qualitatively similar. The differences of progress variable source term retrieved from the manifold of each mechanism resulted in slight differences of flame stabilization locations which effected the LOL predictions. The IDT analysis from the 3D simulations show similar results to the $1 \mathrm{D}$ flamelet results which indicates chemical kinetics is one of the driving factors for the predictions of IDT in FGM approach. Both the Cai mechanism and the Polimi mechanism show good predictability in IDT and LOL. With a higher chemical source term in the ignition region, the Yao mechanism predicted earlier IDT and shorter LOL. Whereas the Luo mechanism consistently overestimated the IDT and LOL due to lower chemical source term values presented in the manifold throughout all regions.

Finally, the effect of chemical mechanisms is further presented in the predictions of combustion recession. The results show that low-temperature chemistry is a driving force for second-stage ignition in diesel spray end-of-injection processes. Clear evidence was found through the comparison of $\mathrm{OH}$ quantities obtained from the Cai mechanism and the Luo mechanism. Originated from the same detailed chemistry, the Cai mechanism presented a stronger prediction for combustion recession due to it's better incorporation of low-temperature chemistry. In the current FGM framework the Yao mechanism predicted the furthest combustion recession phenomenon due to its higher chemical source term in ignition regions which agrees with prior experimental observations showing combustion recession is driven by a series of auto-ignition events.

Although this study has given increased physical insights for the prediction of combustion recession using the FGM approach, there is sill room for improvement in terms of the combustion model. The next step of this study is to include $\widetilde{Z^{\prime \prime 2}}$ in the tabulation process which, as highlighted by previous studies, could increase the diffusion processes in near nozzle regions creating a stronger entertainment flux resulting in further combustion recession.

\section{References}

[1] Converge CFD manual.

[2] C. Bekdemir, E. Rijk, L. Somers, P. Goey, and B. Albrecht. On the application of the flamelet generated manifold (FGM) approach to the simulation of an igniting diesel spray. SAE Technical Papers, 2010-01-0358.

[3] R. Bilger, S. Starner, and R. Kee. On reduced mechanisms for methane air combustion in nonpremixed flames. Combustion and Flame, 80(2):135 - 149, 1990.

[4] Blomberg, C., Zeugin, L., Pandurangi, S., Bolla, M. et al. Modeling Split Injections of ECN Spray A Using a Conditional Moment Closure Combustion Model with RANS and LES. SAE Int. J. Engines, 9(4), January 2016.

[5] M. K. Bobba, C. L. Genzale, and M. P. B. Musculus. Effect of ignition delay on in-cylinder soot characteristics of a heavy duty diesel engine operating at low temperature conditions. SAE Int. J. Engines, 2:911-924, 042009.

[6] L. Cai, L. Kroger, and H. Pitsch. Reduced and optimzed mechanism for n-dodecane oxidation. 15th International Conference on Numerical Combustion, Apr 2015.

[7] Chem1D. One-dimensional laminar flame code, Eindhoven University of Technology. URL http://www. combustion. tue. nl/chemld.

[8] J. M. Desantes, V. Bermudez, J. J. Lopez, and D. Lopez-Pintor. A new method to predict high and low-temperature ignition delays under transient thermodynamic conditions and its experimental validation using a rapid compression-expansion machine. Energy Conversion and Management, 123:512 - 522, 2016.

[9] J. M. Desantes, J. J. Lopez, J. M. Garcia-Oliver, and D. Lopez-Pintor. Experimental validation and analysis of seven different chemical kinetic mechanisms for n-dodecane using a rapid compression-expansion machine. Combustion and Flame, 182:76 - 89, 2017.

[10] U. Egüz, S. Ayyapureddi, C. Bekdemir, B. Somers, and P. de Goey. Modeling fuel spray auto-ignition using the fgm approach: Effect of tabulation method. In SAE 2012 World Congress Exhibition. SAE International, apr 2012. [11] U. Egüz, S. Ayyapureddi, C. Bekdemir, B. Somers, and 
P. de Goey. Manifold resolution study of the FGM method for an igniting diesel spray. Fuel, 113:228-238, 2013.

[12] X. H. Fang, R. Ismail, J. Camm, and M. Davy. Numerical studies of combustion recession on ECN diesel Spray A. ASME. Internal Combustion Engine Division Fall Technical Conference, 2017.

[13] R. Hasegawa and H. Yanagihara. HCCI combustion in DI diesel engine. In SAE Technical Paper. SAE International, 032003.

[14] D. Jarrahbashi, S. Kim, and C. Genzale. Simulation of combustion recession after end-of-injection at diesel engine conditions. Journal of Engineering for Gas Turbines and Power, 139, 032017.

[15] D. Jarrahbashi, S. Kim, B. W. Knox, and C. L. Genzale. Computational analysis of end-of-injection transients and combustion recession. International Journal of Engine Research, 0(0):1468087417701280, 0.

[16] S. Kim, D. Jarrahbashi, and C. Genzale. The role of turbulent-chemistry interaction in simulating end-of-injection combustion transients in diesel sprays. In SAE Technical Paper. SAE International, 032017.

[17] S. Kimura, O. Aoki, H. Ogawa, S. Muranaka, and Y. Enomoto. New combustion concept for ultra-clean and high-efficiency small DI diesel engines. In SAE Technical Paper. SAE International, 101999.

[18] B. W. Knox and C. L. Genzale. Scaling combustion recession after end of injection in diesel sprays. Combustion and Flame, 177(Supplement C):24 - 36, 2017.

[19] Knox, B., Genzale, C., Pickett, L., Garcia-Oliver, J. et al. Combustion Recession after End of Injection in Diesel Sprays. SAE Int. J. Engines, 8(2):679-695, 2015.

[20] P. Kundu, M. M. Ameen, and S. Som. Importance of turbulence-chemistry interactions at low temperature engine conditions. Combustion and Flame, 183:283 298, 2017.

[21] F. Leach, R. Ismail, and M. Davy. Engine-out emissions from a modern high speed diesel engine: The importance of nozzle tip protrusion. Applied Energy, 226:340 - 352, 2018.

[22] Z. Luo, S. Som, S. M. Sarathy, M. Plomer, W. J. Pitz, D. E. Longman, and T. Lu. Development and validation of an n-dodecane skeletal mechanism for spray combustion applications. Combustion Theory and Modelling, 18(2):187-203, 2014.

[23] L. Nicholson, X. Fang, J. Camm, M. Davy, and D. Richardson. Comparison of transient diesel spray break-up between two computational fluid dynamics codes. In WCX World Congress Experience. SAE International, apr 2018.

[24] J. V. Oijen and L. D. Goey. Modelling of premixed laminar flames using flamelet-generated manifolds. Combustion Science and Technology, 161(1):113-137, 2000.

[25] N. Papaioannou, F. C. Leach, M. H. Davy, A. Weall, and B. Cooper. Evaluation of exhaust gas recirculation techniques on a high-speed direct injection diesel engine using first law analysis. Proceedings of the Institution of Mechanical Engineers, Part D: Journal of Automobile Engineering, 0(0):0954407017749110, 0.
[26] Y. Pei, S. Som, E. Pomraning, P. K. Senecal, S. A. Skeen, J. Manin, and L. M. Pickett. Large eddy simulation of a reacting spray flame with multiple realizations under compression ignition engine conditions. Combustion and Flame, 162(12):4442 - 4455, 2015.

[27] E. Ranzi, A. Frassoldati, A. Stagni, M. Pelucchi, A. Cuoci, and T. Faravelli. Reduced kinetic schemes of complex reaction systems: Fossil and biomass-derived transportation fuels. International Journal of Chemical Kinetics, 46(9):512-542.

[28] E. Ranzi, A. Frassoldati, A. Stagni, M. Pelucchi, A. Cuoci, and T. Faravelli. Reduced kinetic schemes of complex reaction systems: Fossil and biomass-derived transportation fuels. International Journal of Chemical Kinetics, 46(9):512-542, 2014.

[29] S. A. Skeen, J. Manin, and L. M. Pickett. Simultaneous formaldehyde PLIF and high-speed schlieren imaging for ignition visualization in high-pressure spray flames. Proceedings of the Combustion Institute, 35(3):3167 3174, 2015.

[30] O. Sogbesan, M. H. Davy, and C. P. Garner. Insights into the hydrocarbon and carbon monoxide emissions in moderately and highly dilute low temperature combustion. Proceedings of the Institution of Mechanical Engineers, Part D: Journal of Automobile Engineering, 228(11):1285-1296, 2014.

[31] G. Stahl and J. Warnatz. Numerical investigation of time-dependent properties and extinction of strained methane and propane-air flamelets. Combustion and Flame, 85(3-4):285-299, 1991.

[32] A. Wehrfritz, O. Kaario, V. Vuorinen, and B. Somers. Large eddy simulation of n-dodecane spray flames using flamelet generated manifolds. Combustion and Flame, 167:113 - 131, 2016.

[33] C. K. Westbrook, W. J. Pitz, O. Herbinet, H. J. Curran, and E. J. Silke. A comprehensive detailed chemical kinetic reaction mechanism for combustion of n-alkane hydrocarbons from n-octane to n-hexadecane. Combustion and Flame, 156(1):181 - 199, 2009.

[34] T. Yao, Y. Pei, B. Zhong, S. Som, and T. Lu. A hybrid mechanism for n-dodecane combustion with optimized low-temperature chemistry. 052015.

[35] X. You, F. N. Egolfopoulos, and H. Wang. Detailed and simplified kinetic models of n-dodecane oxidation: The role of fuel cracking in aliphatic hydrocarbon combustion. Proceedings of the Combustion Institute, 32(1):403 - 410, 2009.

\section{Contact Information}

XiaoHang Fang

xiaohang.fang@eng.ox.ac.uk

\section{Acknowledgements}

The authors would like to thank EPSRC, The China Oxford Scholarship Fund and The Great Britain-China Scholarship Fund for the financial support. We would also like to thank 
Convergent Science Inc for CFD code access and the supporting baseline conditions provided by Kim Sayop and Prof. Genzale from Georgia Institute of Technology.

\section{Definitions/Abbreviations}
AMR Adaptive Mesh Refinement
ASOI After Start of Injection
CDF Counterflow Diffusion Flame
CFD Computational Fluid Dynamics
EOI End of Injection
ECN Engine Combustion Network
FGM Flamelet Generated Manifold Model
HR Homogeneous Reactor
ICDF Igniting Counterflow Diffusion Flame
IDT Ignition Delay Time

KHRT Kelvin-Helmholtz Raleigh-Taylor

LOL Lift-Off Length

LTC Low Temperature Combustion

NTC No Time Counter Model

RANS Reynold Averaged Navier Stokes

SOI Start of Injection

QSS Quasi-steady State

c Progress Variable

Z Mixture Fraction 


\section{SAE19PFL-0169 RESPONSES TO REVIEWERS}

Authors would like to thank the reviewers for their detailed review of the conference paper and suggestions to improve the quality of the paper.

Please find below responses to specific comments given by the reviewers:

Note: All corrections regarding general formatting and presentation have been implemented as per the reviewer suggestions.

\section{Reviewer 1 Responses}

We thank the reviewer for the constructive comments received, which we know makes this a better paper. We observe some low scorings, for example in Conclusions. The SAE scoring system makes the following comment for a score of this value:

Conclusions are unclear and flawed.

Or:

Conclusions are illogical or unsubstantiated.

We are not sure, based on the reviewers comments, where we can improve further in this area as we do believe the conclusions are supported by the facts presented and they are firmly established based on both numerical results and experimental literature. Therefore we would appreciate further guidance or rescoring.

- Could add more detail to the CFD setup (e.g., base grid size). AMR velocity "sub-grid" criteria stated as $0.1 \mathrm{~ms}^{-} 1$, did you mean $\mathrm{m} / \mathrm{s}$ ?

Additional details have been added to the CFD setup.

- A plot showing the ROI profile used would be helpful

The rate of injection used in simulations has been added to the computational setup section.

- Table 2 lower right original mechanism reference needs correction? Don't understand this reference. The reference has been corrected.

- Table 3 could include the measured IDT

Experimental ignition delay time has been added to Table 3

- In section comparing 0D FGM and 1D FGM simulations: Should state in the text which chemical mechanism was used

Figure caption has been amended to include the mechanism used.

- Similar plots at the same times could show equivalence ratio, which would compliment the temperature plots

Thank you for the kind inputs. Additional plots for mixture fraction- temperature space have been added to the discussion

- It's difficult to conclude the differences are due to strain effects in the combustion model, when as is mentioned, the macro flow and mixing also change

Yes the macro flow and mixing also plays a critical role in the two combustion models. We have modified the text with regard to the combustion model comparison study. However it is still reasonable to conclude that the inclusion of strain effects plays a significant effect on the predictions of these two models. Both models use FGM chemistry tabulation approach where the major difference between two tabulation methods lies in the inclusion of strain effects.

- Figure 13 could be expanded upon similar to the suggestions above (i.e., more times, velocity vectors, companion equivalence ratio contours)

Thank you for the kind inputs. Additional plots for mixture fraction-temperature space have been added to the discussion. Further analysis will be included in our next publication 
- Finally, many of the references appear to be incomplete and should be fixed. There should be enough information so that the reader can look up the reference.

The reference list has been corrected to display the appropriate information.

\section{Reviewer 2 Responses}

- Fig. 6: Can you compare the values to measured pressure / heat release? I think this would provide a more meaningful comparison.

Figure 6 (now Figure 7) shows the maximum temperature of the 1D Igniting Counter Flow Diffusion flamelet simulations and not of the ECN Spray A CFD simulations. The figure caption has been changed to highlight this.

- Fig. 7 (now Figure 8): It would be useful to provide insight into why the Yao mechanism shows more activity at low progress than the other mechanisms

The early ignition prediction by the Yao mechanism has been attributed to increased accumulation of $\mathrm{HO} 2$ which is a key species in tracking first stage ignition[1]. It was found by [2] that reactions producing $\mathrm{HCO}$ which is a key species in producing HO2 were enhanced in the Yao mechanism leading to early ignition delay predictions. Additionally, predictions of the high temperature ignition stage which is promoted by the species $\mathrm{H} 2 \mathrm{O} 2$ are also early for the Yao mechanism, as reactions relevant to the production of $\mathrm{H} 2 \mathrm{O} 2$ are highly enhanced in the Yao mechanism compared to the other mechanisms.

- Section: Comparing 0D FGM and 1D FGM Simulations: How closely does the 0D solution using the FGM reproduce the 0D solution obtained through direct integration? This should be discussed if the paper is considered for journal publication.

This comparison has not been made by the authors as it is out of scope of the present study, however, differences between 0D-FGM and Direct Chemistry integration has been made previously by Piehl et al. [3]

- Section: Comparing 0D FGM and 1D FGM Simulations: How sensitive are the solutions to the choice of mapping parameters (e.g., CH2O)?

Expectedly choice of mapping parameters will influence predictions, sensitivity studies have not been conducted by the authors as it is out of scope of the present study, however the selection of $\mathrm{CH} 2 \mathrm{O}, \mathrm{CO}$ and $\mathrm{CO} 2$ has been used widely in FGM simulations of spray combustion [4]

- The authors state that the lack of ability to predict combustion recession for the 0D model is due to "the HR tabulation method's exclusion of diffusion and transport phenomenon." I am surprised by this statement. While the $0 \mathrm{D}$ model does not include laminar species diffusion, it certainly includes turbulent diffusion. I would expect that turbulent diffusion would dominant laminar diffusion in the region of interest. Can the authors comment on this?

In this study the chemistry is detached from the CFD solver. The source terms for chemical reactions are tabulated prior to the CFD solver where the look up is achieved via mixture fraction and progress variable. Although the CFD solver includes turbulent diffusion for both approaches, the inclusion of diffusion process in tabulation methods is different. For homogeneous reactor tabulation (0D FGM approach), each control volume the fuel and air is treated as a well mixed solution therefore lacking the diffusion effects. Whereas the igniting counter flow diffusion tabulation (1D FGM approach) does include varying strain rate effects therefore includes diffusion and transport phenomenon. Similar statements with regard to the differences between two methods can also be found in previous studies.

- Table 4: Please indicate that "Sandia" is the measured value.

The title "sandia" has been changed to "Experiment" .

\section{References}

[1] J. M. Desantes, V. Bermudez, J. J. Lopez, and D. Lopez-Pintor. A new method to predict high and low-temperature ignition delays under transient thermodynamic conditions and its experimental val- 
idation using a rapid compression-expansion machine. Energy Conversion and Management, 123:512 $-522,2016$.

[2] J. M. Desantes, J. J. Lopez, J. M. Garcia-Oliver, and D. Lopez-Pintor. Experimental validation and analysis of seven different chemical kinetic mechanisms for n-dodecane using a rapid compressionexpansion machine. Combustion and Flame, 182:76 - 89, 2017.

[3] J. A. Piehl, O. S. Abianeh, A. Goyal, and L. Bravo. Turbulent spray combustion modeling using various kinetic solvers and turbulence models. ASME. J. Eng. Gas Turbines Power, 140(12):121503121503-18, 2018.

[4] A. Wehrfritz, O. Kaario, V. Vuorinen, and B. Somers. Large eddy simulation of n-dodecane spray flames using flamelet generated manifolds. Combustion and Flame, 167:113 - 131, 2016. 